\title{
ESTABLISHMENT OF A SCALE OF COLOR TEMPERATURE
}

\author{
By H. T. Wensel, D. B. Judd, and Wm. F. Roeser
}

\section{ABSTRACT}

A number of 400-watt projection lamps were color matched with black bodies immersed in freezing platinum, rhodium, and iridium. From these lamps working standards of color temperature were prepared, interpolation between the three fundamental points being accomplished by making use of the systematic difference between the color temperature of the lamp and the brightness temperature of the inside of a particular turn of the coiled tungsten filament.

These working standards embody a reproducible scale of color temperature which is consistent with the International Temperature Scale within $5^{\circ} \mathrm{K}$ everywhere in the range from 2,000 to $2,800 \mathrm{~K}$.

The new scale assigns higher values to any given source than the scale previously used at the Bureau of Standards and which was supposed to be the same as the Nela scale of color temperature. The differences are $22^{\circ} \mathrm{K}$ at the platinum point and $14^{\circ} \mathrm{K}$ at the rhodium and the iridium points.

CONTENTS

I. Introduction

II. Scales now in use.

III. Present work

1. Basis of the present scale

2. Optical arrangements .

3. Standard lamps _...... 532

4. Freezing metals

5. Results

6. Interpolation between fixed points

IV. Discussion of results

1. Analysis of errors

2. Comparison with previous scales

\section{INTRODUCTION}

The International Commission on Illumination at its 1931 meeting in Cambridge ${ }^{1}$ adopted, among other things, a recommendation for standard illuminants, which has been translated as follows, "It is recommended that the following three illuminants be adopted as standards for the general colorimetry of materials:

A. A gas-filled lamp of color temperature $2,848^{\circ} \mathrm{K}$.

B. The same lamp used in combination with a filter composed of a layer one centimeter thick of each of two solutions, $\mathrm{B}_{1}$ and $\mathrm{B}_{2}$, etc.

C. The same lamp used in combination with . . . . two solutions, $\mathrm{C}_{1}$ and $\mathrm{C}_{2}$, etc."

The ability of an experimenter to set up any one of these recommended standard illuminants depends on his ability to operate a gasfilled tungsten lamp at 2,848 $\mathrm{K}$ color temperature. No statement was

\footnotetext{
1 Proceedings of the 8th session, Commission Internationale de l'Élairage, Cambridge, Sept. 1931, p. 19.
} 
made, however, as to how the lamp should be brought to this color temperature nor what existing color temperature scales, if any, should be accepted as authoritative. A feeling apparently existed among the representatives from the several countries that the realization of the standard illuminants was uncertain in this respect because informal arrangements were made at the time for an intercomparison of the color temperature scales then in use in England, Germany, France, and the United States.

The temperature ${ }^{2}$ of a hollow enclosure or black body which color matches a given illuminant is called the color temperature of that illuminant. In accord with this definition, the direct visual comparison of such an illuminant with a black body of known or measurable temperature is probably the most certain method of determining its color temperature. This method has presumably been used in the establishment of the various scales in use except for the higher temperatures. At the higher temperatures, it is difficult to control the temperature of black bodies and therefore the method of visual comparison has been supplemented by indirect methods involving a calculation of the color temperature from the measured spectral energy distribution. In one of these, called the red-blue ratio method, the color temperature of an illuminant is taken to be that of a black body which radiates at two selected wave lengths in the same ratio as the illuminant in question. In another method the temperature of that black body is selected whose spectral energy distribution throughout the visible spectrum, most nearly "fits" that of the illuminant. Several criteria, each yielding a slightly different result and none satisfactory from a theoretical standpoint, are available for thus selecting the black body which will presumably give the best color match.

\section{SCALES NOW IN USE}

There are almost no data available on the agreement among the scales used in different countries nor on the basis for any of these scales except the one used in the United States. In this country the scale universally used is the one established and maintained by the Nela Research Laboratory.

The high-temperature scale used at that laboratory was based on Wien's law of radiation using $1,828 \mathrm{~K}$ for the palladium point and $1.435 \mathrm{~cm}$ degrees for the second constant in the radiation formula. The Nela color temperature scale was established up to about 2,600 $\mathrm{K}$ by direct comparison with a black body in the form of a carbon tube furnace. From correspondence with the Nela laboratory we understand that the scale was then extended up to 3,000 K by indirect methods and considerably less confidence was therefore placed in this portion of the scale.

The scale in use at the Bureau of Standards since 1922 was based on 3 lamps obtained from and calibrated by the Nela laboratory, 2 in 1920 and 1 in 1922 . Of these the first was calibrated at $2,360 \mathrm{~K}$, the second throughout the range 1,719 to $2,448 \mathrm{~K}$, and the third throughout the range 2,334 to $2,820 \mathrm{~K}$. Meanwhile the spectral energy distribution of a 500-watt stereopticon lamp, designated as

\footnotetext{
${ }^{2}$ Expressed in this work on the International Scale. This temperature scale was adopted in 1927 by 31 nations and is in almost universal use. On this scale the freezing point of gold is defined as $1,063 \mathrm{C}$ and the value of $\mathrm{C}_{2}$ is taken as $1.432 \mathrm{~cm}$ deg.
} 
B.S. no. 1,717 , had been determined radiometrically ${ }^{3}$ at a particular voltage and used to deduce a color temperature ${ }^{4}$ of $2,848 \mathrm{~K}$. Another lamp, which had been color matched against B.S. no. 1,717, was then sent to the Nela laboratory and compared with their standard. The average of four determinations ${ }^{5}$ was given as $2,848 \mathrm{~K}$. The exactness of this agreement was apparently accidental and has created the impression that this point on the scale was determined with far more accuracy than was actually the case.

All three of the lamps received from the Nela laboratory had thus been calibrated at $2,360 \mathrm{~K}$ and comparisons indicated that they agreed at this point to about $5^{\circ} \mathrm{K}$. Slight adjustments in the assigned voltages were accordingly made to make them agree exactly. The situation was not so fortunate at the 2,848 point. The Bureau had only one lamp calibrated by the Nela laboratory at this point. It was found that this lamp (a duplicate of B.S. 1,717) operated to reproduce the 2,848 point color matched approximately the lamp calibrated from 2,334 to $2,820 \mathrm{~K}$ when operated to reproduce 2,820 $\mathrm{K}$, although the latter lamp is too purple to match exactly the 2,848 lamp at any voltage. The scale largely used at the Bureau since 1922 has been based on the $2,848 \mathrm{~K}$ point as embodied in lamp B.S. 1,717 and on the Nela $2,360 \mathrm{~K}$ point, interpolation being made by means of the rotatory dispersion colorimeter. ${ }^{6}$ In 1932 another duplicate of B.S. 1,717 was sent to the lamp-development laboratory at Nela Park and a check to $2^{\circ} \mathrm{K}$ obtained at $2,848 \mathrm{~K}$.

\section{PRESENT WORK}

\section{BASIS OF THE PRESENT SCALE}

The purpose of the present work is to establish a scale of color temperature based upon thermometric fixed points, by color matching a number of incandescent lamps with hollow enclosures immersed in freezing metals. For this purpose the following three metals are available whose freezing points have been accurately determined and are spaced at suitable intervals:

1. Platinum, freezing point 7

2. Rhodium, freezing point ${ }^{8}-$ $2046 \pm 1^{\circ} \mathrm{K}$

One obvious advantage of the scale established on this basis is the means available for checking the lamp standards at the three fixed points at any time this may be deemed necessary. Moreover, in working with the invariable light sources provided by hollow enclosures immersed in freezing metals the accuracy attainable is of a higher order than has been attained by other methods.

\section{OPTICAL ARRANGEMENTS}

The colorimetric comparisons were made with a Lummer-Brodhun photometer head from which the contrast strips had been removed. The field is the familiar double-trapezoid type, $9^{\circ}$ wide by $13^{\circ}$ high.

\footnotetext{
3 For complete details see B.S. Scientific Papers, vol. 18, p. 221, 1922-23.

4 Quite apart from the uncertainty of the radiometric measurements, the uncertainty in this deduced value may be judged from the fact that Priest (B.S. Scientific Papers, vol. 17, p. 231, 1921) at first deduced $2,830 \mathrm{~K}$ from the same data and that the method of Davis (B.S. Jour. Research, vol. 7, p. 671, 1931) yields $2,860 \mathrm{~K}$.

5 Reported Aug. 11, 1921.

6 I. G. Priest, B.S. Scientific Papers, vol. 18, p. 221, 1922.

7 Roeser, Caldwell, Wensel, B.S. Jour. Research, vol. 6, p. 1119, 1931.

8 Roeser and Wensel, B.S. Jour. Research, vol. 12, p. 519, 1934.

- Henning and Wensel, B.S. Jour. Research, vol. 10, p. 809, 1933.
} 
The substitution method was used. The photometer field was illuminated in essentially the same manner as described in the work ${ }^{10}$ on the Waidner-Burgess Standard of Light, one side of the photometer head being illuminated either with light from the black body or with light from the standard lamp. The other side of the photometer head was illuminated by light from a comparison lamp.

It does not appear possible to dispense with the lens between the black body and the photometer. Without a lens, the illumination is much too low for accurate measurements. Moreover, this illumination coming partly from the opening in the black body and partly from the regions around this opening would be considerably redder than the light from the opening which is characteristic of the fixed point. The lens, however, images these colder parts outside the photometric field so that only light from the opening itself enters the photometer. The relative aperture of the lenses used was $f / 11$ in each case. Inasmuch as a lens must be used, the use of a prism adds no further difficulty since the chromatic effect of the combination can be determined as readily as that of a lens alone.

Several prisms and about a dozen lenses were examined without finding a combination sufficiently free from selectivity to yield a good color match. All were slightly greenish. Since, as will appear later, the black body was an exact color match for the standard lamps when burned at the proper voltage, the latter did not yield a color match at any voltage with the black body viewed through the lens and prism. The chromatic effect of the lens and prism could be eliminated by placing them in front of the standard lamps as well. This, however, would require frequent time-consuming realinements of the optical parts and was found to be unnecessary since a piece of ordinary window glass of suitable thickness placed before the standard lamp permitted a color match with the black bodies as seen through the lens and prism. Evidently a "green" comparison lamp was required and this was obtained by a filter made of two opposing wedges of window glass placed in front of the comparison lamp. This filter is not very selective; the thickness of wedge required for one lens-prism combination transmits only 7 percent more in the middle of the spectrum than at the ends. The other combination requires a filter selective by only 4 percent. As will appear later, the two lens-prism combinations gave essentially identical results.

The greenish wedge in front of the comparison lamp has the same effect as a comparison lamp with a greenish globe and (as long as we are able to secure a color match) does not concern us further. The wedge setting was not changed during any set of measurements. Since both the black body viewed through the lens and prism and the standard lamps viewed through the selected piece of window glass matched the "green" comparison lamp, it follows that the black body and the standard lamps both viewed directly can be color matched if the selective effect of the piece of window glass is the same as that of the lens and prism. This equality was established for two lens-prism combinations experimentally.

A tungsten lamp was color matched against the "green" comparison lamp, first with the lens and prism interposed and then with the piece of window glass interposed. In each case the color match was perfect but a very small voltage difference was observed in the two settings,

${ }^{10}$ Wensel, Roeser, Barbrow, and Caldwell, B.S. Jour. Research, vol. 6, p. 1103, 1931. 
indicating that the equivalence between the piece of window glass and the lens-prism combination was not exact.

These voltage differences, equivalent to differences in color temperature as shown in columns 2 and 4 of table 1, were applied to the results obtained in the main body of the work. An independent check on these corrections was made by measuring separately the effect of the window glass and each of the two lens-prism combinations. In these measurements the slight green difference had to be tolerated; hence the accuracy of the corrections obtained by subtraction (columns 3 and 5) was relatively low. However they were found to equal, within experimental error, the corrections measured directly by interchanging the two devices. Another check on these corrections was obtained by using both lens-prism combinations in the actual work and noting the agreement obtained in the two cases after the corresponding corrections had been applied.

TABLE 1.-Corrections to be applied when using window glass to compensate for lens-prism combination

\begin{tabular}{|c|c|c|c|c|}
\hline \multirow{2}{*}{$\begin{array}{l}\text { Tempera- } \\
\text { ture of } \\
\text { source }\end{array}$} & \multicolumn{2}{|c|}{$\begin{array}{l}\text { Correction when using } \\
\text { lens no. } 1\end{array}$} & \multicolumn{2}{|c|}{$\begin{array}{c}\text { Correction when using } \\
\text { lens no. } 2\end{array}$} \\
\hline & $\begin{array}{c}\text { By direct } \\
\text { measure- } \\
\text { ment }\end{array}$ & $\begin{array}{l}\text { By sub- } \\
\text { traction }\end{array}$ & $\begin{array}{c}\text { By direct } \\
\text { measure- } \\
\text { ment }\end{array}$ & $\begin{array}{l}\text { By sub- } \\
\text { traction }\end{array}$ \\
\hline $\begin{array}{l}{ }^{\circ} K \\
2,046 \\
2,239 \\
2,727\end{array}$ & $\begin{array}{l}{ }^{\circ} K \\
\\
\\
\\
\\
\\
\\
0\end{array}$ & $\begin{array}{r}{ }^{\circ} K \\
0 \\
-2 \\
+4\end{array}$ & $\begin{array}{c}{ }^{\circ} K \\
\text { Not used } \\
-6\end{array}$ & $\begin{array}{c}{ }^{\circ} K \\
-2 \\
\text { Not used } \\
-7\end{array}$ \\
\hline
\end{tabular}

\section{STANDARD LAMPS}

An extensive study has been made of the aging characteristics of several types of available lamps. ${ }^{11}$ As a result the type selected for this work was a 400 -watt mogul base projection lamp having a coiled monoplane filament in a tubular bulb. At 110 volts these lamps operate at a color temperature of $3,100 \mathrm{~K}$ where they have a total life of only 50 hours. At $2,727 \mathrm{~K}$ however, their qualities are remarkably constant, the color temperature (after the initial half hour) decreasing at the rate of only $0.03^{\circ} \mathrm{K}$ per hour of use.

\section{FREEZING METALS}

The technique employed in melting and freezing the three metals is exactly the same as that used in the freezing point determinations and the work on the Waidner-Burgess Standard of Light. In the case of rhodium, which must be melted in vacuo and observations therefore made through a furnace window, two pyrex windows were used, one on the evacuated tube containing the crucible and the other placed in front of the standard lamps. An interchange of these two windows, when color matching two lamps, showed that no difference between them could be detected. In this work the technique developed in the freezing point determinations made it possible to avoid trouble from film collecting on the window used to seal

11 D. B. Judd,Jour. Opt. Soc. Am., vol. 23, p. 118, 1933. 
the tube containing the rhodium. After a series of observations at the rhodium point the window was removed and observations made on a tungsten lamp first through $\mathrm{P}_{1}$ (the window used on the furnace) and then through $\mathrm{P}_{2}$, the compensating plate. The voltage of the lamp observed alternately through these was maintained constant and the values in table 2 are settings on the comparison lamp to produce a color match. Table 2 shows also the precision attainable in color matching with a Lummer-Brodhun contrast photometer.

TABLE 2.-Test showing absence of error due to film on pyrex plate $P_{1}$

[Lamp voltage $44.0 \mathrm{v}$ ]

\begin{tabular}{|c|c|c|c|c|c|}
\hline 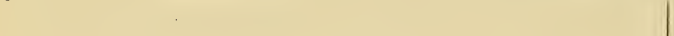 & \multicolumn{5}{|c|}{ Observations through- } \\
\hline & $\mathbf{P}_{1}$ & $\mathbf{P}_{2}$ & $\mathbf{P}_{1}$ & $\mathbf{P}_{2}$ & $\mathbf{P}_{1}$ \\
\hline Settings on voltage of comparison lamp to produce color match. & $\left(\begin{array}{c}v \\
42.1 \\
41.9 \\
41.8 \\
42.1 \\
42.2 \\
42.2\end{array}\right.$ & $\begin{array}{c}v \\
42.2 \\
42.2 \\
41.9 \\
42.2 \\
42.0 \\
42.2\end{array}$ & $\begin{array}{c}v \\
42.2 \\
42.0 \\
42.0 \\
41.9 \\
42.2 \\
42.1\end{array}$ & $\begin{array}{c}\text { ๊ } \\
41.9 \\
41.8 \\
41.8 \\
41.9 \\
41.8 \\
42.1\end{array}$ & $\begin{array}{l}v \\
42.0 \\
42.2 \\
42.0 \\
42.2 \\
42.0 \\
41.9\end{array}$ \\
\hline Mean.-...... & 42.05 & 42.12 & 42.07 & 41.88 & 42.05 \\
\hline
\end{tabular}

\section{RESULTS}

Three groups of three lamps each were color matched with the black bodies, one group at each of the thermometric fixed points. In making observations each observer made 6 settings on 1 lamp, 6 settings on the black body, 6 settings on a second lamp, 6 additional settings on the black body, and finally 6 settings on the third lamp. Observer KSG was available only part of the time and did not make observations when lens no. 2 was employed. Observations with the second lens-prism combination were not made at the rhodium point but the results at the other two points establish the fact that the same result is obtained with each lens. The results of the comparisons are given in tables 3,4 , and 5 .

TABLE 3.-Voltage on lamps to match black body at the platinum point (2,046 K)

[A change of 1 volt produces a change of $20^{\circ} \mathrm{K}$ ]

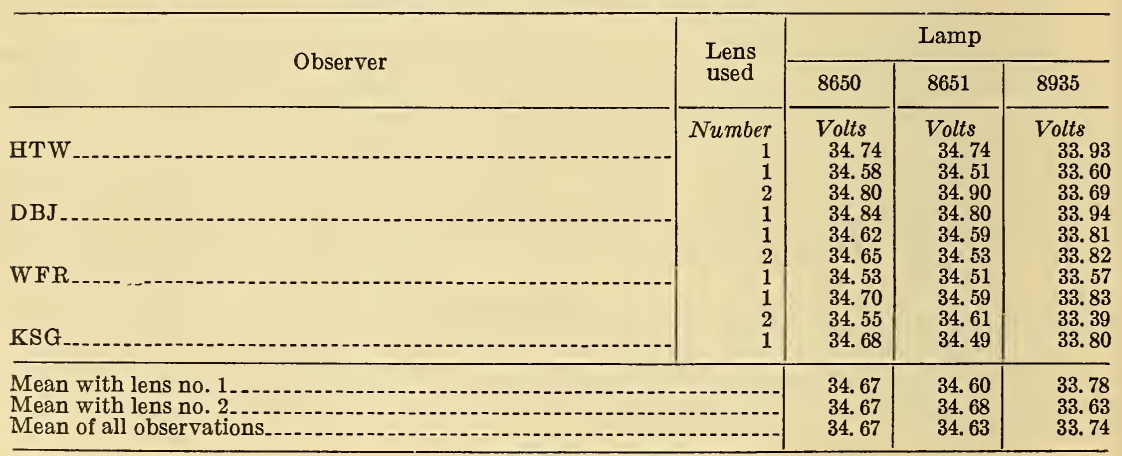


TABLE 4.-Voltage on lamps to match black body at the rhodium point (2,239 $\mathrm{K})$ [A change of 1 volt produces a change of $17^{\circ} \mathrm{K}$ ]

\begin{tabular}{|c|c|c|c|c|}
\hline \multirow{2}{*}{ Observer } & \multirow{2}{*}{$\begin{array}{l}\text { Lens } \\
\text { used }\end{array}$} & \multicolumn{3}{|c|}{ Lamp } \\
\hline & & 9023 & 9024 & 9025 \\
\hline $\begin{array}{l}\text { HTW } \\
\text { DBJ } \\
\text { WFR }\end{array}$ & $\begin{array}{r}\text { Number } \\
1 \\
1 \\
1 \\
1 \\
1 \\
1\end{array}$ & $\begin{array}{l}\text { Volts } \\
44.20 \\
44.20 \\
44.26 \\
44.23 \\
44.28 \\
44.17\end{array}$ & $\begin{array}{l}\text { Volts } \\
44.40 \\
44.40 \\
44.34 \\
44.36 \\
44.30 \\
44.19\end{array}$ & $\begin{array}{l}\text { Volts } \\
44.23 \\
44.24 \\
44.27 \\
44.23 \\
44.23 \\
44.20\end{array}$ \\
\hline Mean & $-\cdots$ & 44.22 & 44.33 & 44.23 \\
\hline
\end{tabular}

TABLE 5.- Voltage on lamps to match black body at the iridium point (2,727 K)

[A change of 1 volt produces a change of $14^{\circ} \mathrm{K}$ ]

\begin{tabular}{|c|c|c|c|c|}
\hline \multirow{2}{*}{ Observer } & \multirow{2}{*}{$\begin{array}{l}\text { Lens } \\
\text { used }\end{array}$} & \multicolumn{3}{|c|}{ Lamp } \\
\hline & & 8934 & 8936 & 8937 \\
\hline $\begin{array}{l}\mathrm{HTW} \\
\mathrm{DBJ} \\
\mathrm{WFR} \\
\mathrm{KSG}\end{array}$ & $\begin{array}{r}\text { Number } \\
1 \\
2 \\
1 \\
2 \\
1 \\
2 \\
1\end{array}$ & $\begin{array}{l}\text { Volts } \\
75.51 \\
75.38 \\
75.56 \\
75.47 \\
75.52 \\
75.56 \\
75.55\end{array}$ & $\begin{array}{c}\text { Volts } \\
75.23 \\
74.93 \\
75.14 \\
75.00 \\
74.82 \\
75.02 \\
74.85\end{array}$ & $\begin{array}{l}\text { Volts } \\
75.24 \\
75.38 \\
75.33 \\
75.24 \\
75.53 \\
75.24 \\
75.50\end{array}$ \\
\hline $\begin{array}{l}\text { Mean with lens no. } 1 \\
\text { Mean with lens no. } 2 \\
\text { Mean of all observations }\end{array}$ & 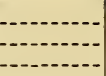 & $\begin{array}{l}75.54 \\
75.47 \\
75.51\end{array}$ & $\begin{array}{l}75.01 \\
74.98 \\
75.00\end{array}$ & $\begin{array}{l}75.40 \\
75.29 \\
75.35\end{array}$ \\
\hline
\end{tabular}

The 3 points on the color-temperature scale, as embodied in the 9 lamps designated as reference standards, were then transferred to 3 working standards, each of these 3 lamps being calibrated in this way at all 3 points. In making the transfers, data were obtained on the differences between the three reference standards of each group. The three reference standards embodying the platinum point had a total spread of $1.9^{\circ}$ $\mathrm{K}$; the total spread at the rhodium and iridium points was 1.2 and $0.9^{\circ}$ $\mathrm{K}$, respectively. The precision of setting was lowest at the platinum point because the field brightness was low, and this probably accounts for the greater spread. The results indicate that the overall precision is very near the limit attainable in color temperature measurements.

\section{INTERPOLATION BETWEEN FIXED POINTS}

The extensive work done at the Nela Research Laboratory on the properties of tungsten has established the fact that a given change in brightness temperature corresponds to an approximately equal change in color temperature of a given specimen of tungsten. This offered a simple means of determining the color temperature of the 3 working standards at voltages between those at which these lamps match the 3 black bodies immersed in freezing metals.

The inside portions of a coiled tungsten filament approximate a black body and have a color temperature below that of the outside portions. The color temperature of the lamp as a whole is somewhere between. The turns near the ends of the coils are relatively cold, but they are few in number, radiate less, and do not have a marked effect upon the color temperature of the lamp.

Lamp 9022, one of the three working standards, was operated at $2,727 \mathrm{~K}$ color temperature and the coils were explored with an optical 
pyrometer to locate the brightest turn. The brightness temperature $\left(\mathrm{T}_{0.65}\right)$ of the inside of this turn was found to be $2,662 \mathrm{~K}$, while that of the outside was $2,486 \mathrm{~K} .{ }^{12}$ Thus the color temperature of the lamp is obtained, at this voltage, by adding $65^{\circ}$ to the reading of the optical pyrometer when sighted upon the inside of this turn. Considerable variation was found from turn to turn in the brightness temperature, especially toward the ends of the coils. For a particular turn, however, the difference between the color temperature of the whole lamp and the brightness temperature inside the turn will obviously be a function of the voltage. For the brightest turn of lamp 9022, this difference was respectively $22^{\circ}, 31^{\circ}$, and $65^{\circ} \mathrm{K}$ at the voltages corresponding to the 3 fixed points platinum, rhodium, and iridium, see

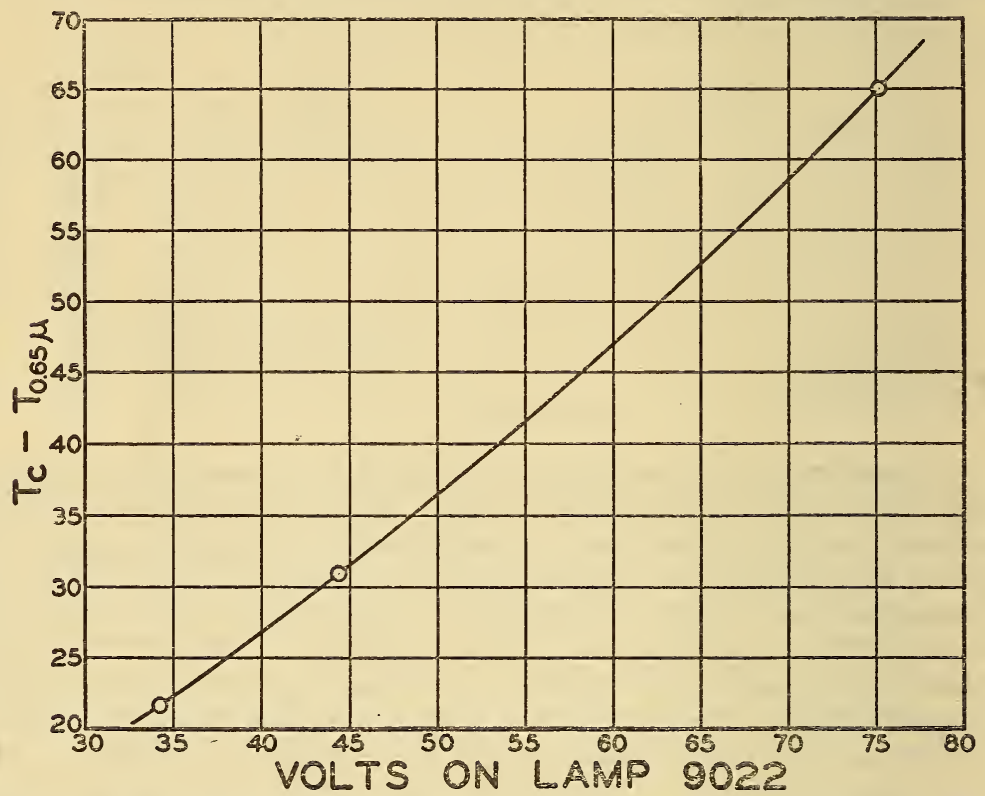

FIGURE 1.-Difference between color temperature of lamp and apparent temperature of the inside of the brightest turn as a function of voltage.

figure 1. By using this curve the color temperature for any voltage may be obtained from an optical pyrometer reading on the brightest turn which we may call A. This was done for six intermediate voltages. The entire process was then repeated using two other turns $\mathrm{B}$ and $\mathrm{C}$ of this same lamp, see table 6 . The differences for these turns were greater than for $\mathrm{A}$, being respectively $78^{\circ}$ and $123^{\circ} \mathrm{K}$ at color temperature $2,727 \mathrm{~K}$. The interpolated values of color temperature, as shown in table 6, may all be accurately represented by the formula,

$$
T_{c}=625+242.5 \sqrt{V}
$$

The values in table 6 have been given merely to demonstrate that the interpolated values do not depend upon the particular turn observed with the optical pyrometer. The results for the other two

12 From this figure and the radiation characteristics of tungsten (Forsythe \& Worthing, Astrophys. Jour. vol. $61, \mathrm{p} .146,1925)$ the true temperature of this turn was calculated as $2,717 \mathrm{~K}$ and the color temperature of the outside portion as $2,785 \mathrm{~K}$. 
lamps may be expressed by similar relations. The formulas for the three lamps are as follows:

$$
\begin{array}{ll}
\text { Lamp 9020, } & T_{c}=617+241.8 \sqrt{V} \\
\text { Lamp 9021, } & T_{c}=620+243.6 \sqrt{\bar{V}} \\
\text { Lamp 9022, } & T_{c}=625+242.5 \sqrt{V}
\end{array}
$$

\begin{tabular}{|c|c|c|c|c|c|}
\hline \multirow{2}{*}{ Volts } & \multicolumn{3}{|c|}{ Turn } & \multirow{2}{*}{$\begin{array}{c}\text { Mean for } \\
3 \text { turns }\end{array}$} & \multirow{2}{*}{$\begin{array}{c}\text { By for- } \\
\text { mula } \\
T_{c}=a+ \\
b \sqrt{V}\end{array}$} \\
\hline & A & B & $\mathrm{C}$ & & \\
\hline $\begin{array}{l}34.32 \\
37.10 \\
40.16 \\
49.26 \\
55.15 \\
61.17 \\
68.08\end{array}$ & $\begin{array}{l}{ }^{\circ} K \\
2,046 \\
2,104 \\
2,163 \\
2,239 \\
2,329 \\
2,426 \\
2,525 \\
2,624 \\
2,727\end{array}$ & $\begin{array}{l}{ }^{\circ} K \\
2,046 \\
2,105 \\
2,160 \\
2,239 \\
2,326 \\
2,423 \\
2,523 \\
2,623 \\
2,727\end{array}$ & $\begin{array}{l}{ }^{\circ} K \\
2,046 \\
2,100 \\
2,163 \\
2,239 \\
2.327 \\
2,427 \\
2,524 \\
2,626 \\
2,727\end{array}$ & $\begin{array}{l}{ }^{\circ} K \\
2,046 \\
2,103 \\
2,162 \\
2,239 \\
2,327 \\
2,425 \\
2,524 \\
2,624 \\
2,727\end{array}$ & $\begin{array}{l}{ }^{\circ} K \\
2,046 \\
2,102 \\
2,162 \\
2,238 \\
2,328 \\
2,426 \\
2,522 \\
2,626 \\
2,727\end{array}$ \\
\hline
\end{tabular}

TABLE 6.-Interpolated values of color temperature for lamp 9022

These equations are merely empirical relations which happen to be applicable to this particular type of lamp.

It may be noted that the scale can be extended both downward and upward (say to 2,848 K) either by these formulas or by reference to brightness temperature, or by suitable filters of known spectral transmission, such as the Davis-Gibson liquid filters. ${ }^{13}$

\section{DISCUSSION OF RESULTS}

\section{ANALYSIS OF ERRORS}

In estimating the errors in the present scale as embodied in the 3 groups of reference standards it must be remembered that the temperatures of the immersed black bodies are known somewhat more accurately than the freezing points of the pure metals. For example, in assigning an uncertainty of $3^{\circ}$ to the freezing point of iridium allowance was made for possible impurities in the metal used and for the fact that the black body enclosure may be at a slightly lower temperature than that of the metal in which it is immersed. The temperature of the black body itself which is all that matters in the present work, was determined with an uncertainty of less than $2^{\circ}$. This arises through uncertainty in measuring the angular aperture of the sector disk, through uncertainty in the effective wave length of the red filter and through the usual experimental uncertainty of photometric matching.

In table 7 is given the error analysis for the individual reference standards. Wherever possible the uncertainties are computed as 4.9 times the probable error; this product has sometimes been called the "huge error" because it is an error such that the chance of occurrence of an equal or greater error is only one in a thousand. In cases which do not permit such a computation, the uncertainty given approximates the huge error as closely as can be estimated. The uncertainty of

13 B.S. Miscellaneous Pub. 114, 1931. 
any individual working standard is slightly greater than the values given in table 7 because of the error introduced by the additional color matching, but it is estimated as nowhere greater than $5^{\circ}$.

\section{TABLE 7.-Analysis of errors for the individual reference standards}

\begin{tabular}{|c|c|c|c|}
\hline Color temperature & $2,046 \mathrm{~K}$ & $2,239 \mathrm{~K}$ & $2,727 \mathrm{~K}$ \\
\hline $\begin{array}{l}\text { Uncertainty in temperature of cavity } \\
\text { Experimental uncertainty of color matching } \\
\text { Uncertainty in lens-prism-compensator correction (table 1) }\end{array}$ & $\begin{array}{r}{ }^{\circ} K \\
1.1 \\
3.2 \\
2.4\end{array}$ & $\begin{array}{r}\circ K \\
1.4 \\
2.2 \\
2.0\end{array}$ & $\begin{array}{r}\circ K \\
\\
1.9 \\
1.7 \\
1.8\end{array}$ \\
\hline Total uncertainty (square root of the sum of the squares) & 4.1 & 3.3 & 3.1 \\
\hline
\end{tabular}

\section{COMPARISON WITH PREVIOUS SCALES}

The question of greatest interest to people who depend on measurements of color temperatures probably is, "How much does the present scale differ from previous scales?"

As stated in section II, the Bureau had one lamp calibrated by the Nela Research Laboratory from 1,719 to $2,448 \mathrm{~K}$. When operated at the voltage certified to give $2,046 \mathrm{~K}$, this lamp has a color temperature of $2,068 \mathrm{~K}$ on the present scale. When operated at the voltage giving $2,239 \mathrm{~K}$ on the Nela scale, it has a color temperature of $2,253 \mathrm{~K}$.

The Bureau had a second lamp calibrated from 2,334 to $2,820 \mathrm{~K}$ by the Nela laboratory. When this lamp was operated to yield $2,727 \mathrm{~K}$ on the Nela scale, it would have to be assigned a value of about $2,775 \mathrm{~K}$ to agree with the present scale, but this lamp is too purple to color match the other lamps at any voltage.

The Bureau of Standards lamp certified by the Nela laboratory to yield $2,848 \mathrm{~K}$ can be operated to yield $2,727 \mathrm{~K}$ on the Nela scale by recourse to the relation between voltage and color temperature. When this is done its color temperature is $2,741 \mathrm{~K}$.

The differences between the new scale and that previously maintained at the Bureau are summarized in table 8. It is not known however, how accurately these differences apply to the scale as maintained at Nela Park.

TABLE 8.-Difference between present scale and previous scale

\begin{tabular}{|c|c|c|c|}
\hline \multirow[b]{2}{*}{ Lamp } & \multicolumn{2}{|c|}{ Color temperature } & \multirow[b]{2}{*}{ Difference } \\
\hline & $\begin{array}{c}\text { On pre- } \\
\text { vious scale }\end{array}$ & $\begin{array}{c}\text { On present } \\
\text { scale }\end{array}$ & \\
\hline $\begin{array}{l}\mathrm{A}-1 \\
\mathrm{~B}-\mathrm{C} \\
\mathrm{C}-\mathrm{d}\end{array}$ & $\begin{array}{c}{ }^{\circ} K \\
2,046 \\
2,239 \\
2,727 \\
2,727\end{array}$ & $\begin{array}{c}{ }^{\circ} K \\
2,068 \\
2,253 \\
2,775 \\
2,741\end{array}$ & $\begin{array}{rr} & \\
& \\
& 22 \\
14 & 14 \\
148 & 14 \\
& 14\end{array}$ \\
\hline
\end{tabular}

1 The old Bureau scale was not based on this lamp.

Acknowledgment is made to K. S. Gibson who served as one of the observers in part of the work and who, together with D. B. Judd, made the transfers to the working standards and the comparisons with the Nela scale.

Washington, March 3, 1934. 